\title{
Evaluation of the plasticity index as a scuffing criterion
}

\author{
K.-B. Park and K.C. Ludema \\ Mechanical Engineering Department, The University of Michigan, Ann Arbor, MI 48109-2125 (USA)
}

(Received August 12, 1993; accepted November 18, 1993)

\begin{abstract}
The plasticity index has often been invoked as an indicator of the most likely condition for scuffing of metals. The particular condition for initiating scuffing was thought to be $2 \%$ plastic strain in contacting asperities, which would lead to adhesion between asperities.

Experiments were done to validate the hypothesis using low alloy steels and stainless steel, lubricated with plain mineral oil and mineral oil containing $1 \%$ stearic acid, in slow single-pass sliding and in repeat pass sliding. Some experiments showed an influence of asperity slope on scuffing load as suggested by the plasticity index. Most experiments showed no such infuence. All experiments showed that a great amount of plastic flow occurred before scuffing occurred.
\end{abstract}

\section{Introduction}

Lubricated sliding surfaces sometimes wear away progressively and in a manner that appears to be related to the severity of contact and efficacy of lubrication. Identical systems may on occasion become inoperable rather quickly at almost any point in their expected lifetime. Wear life in the progressive mode is often fairly reliably predicted, but life in the other, the catastrophic mode, is not. Whereas there are several rather detailed and science-based criteria for predicting catastrophic failure of surfaces, none is applicable in product design. The consequence is that all lubricated systems, such as prosthetic animal joints, mechanical machinery and heart valves are considerably over designed in order to avoid catastrophic failure of the few.

The catastrophic mode of surface failure is sometimes referred to as scuffing, or scoring, or perhaps galling or seizing. Many of these terms are old and poorly understood, and apply principally to ductile metals. Each of these terms has several technical meanings and produces several different end results. In the interest of reducing the number of terms to be used in this paper some definitions will be proposed.

Seizing is a term that describes the severe damage of sliding surfaces where the driving system cannot provide sufficient force to overcome friction: the sliding pair ceases to slide. Galling is a process of surface roughening that results from high contact pressure and high traction, at slow speed generally and without any lubricant other than the native oxide and adsorbed gas on the surfaces. Most likely the failure of lubricated surfaces within the first few cycles of contact is similar to the galling process but failure at a later stage is different. Scuffing and scoring by contrast usually refer to modes of failure of well-lubricated metal parts. Subjectively, they are described as different from galling and seizing, but the initiating mechanism of all may be the same.

\section{History of thought on scuffing of metals: literature survey}

The OECD defines scuffing as an adhesive failure, implying that the two sliding surfaces become welded or bonded together [1]. This cannot be taken as a general definition since surfaces (other than a shaft in a bearing) that fail quickly can usually be separated without applying force to separate them. The implication in the definition of the OECD may be that the adhesive mechanisms of friction and wear are operative in scuffing, but details of the manner by which adhesion occurs are not provided. Further, it is not particularly useful to attribute scuffing to adhesion because in the broader sense, all resistance to sliding and all forms of wearing can be attributed to adhesion.

Several attempts have been published to establish the conditions under which scuffing will occur. These have become known as scuffing criteria. There are several, but the most prominent three are the $A$ criterion, the maximum temperature criterion and the plasticity index criterion. Each of these suggests that a given condition marks the boundary between safe and unsafe 
operation of sliding surfaces. None of these criteria is valid, though they may identify conditions for very safe operation. They cannot be used, however, to describe the outer envelope of safe operation. The major reason for the inapplicability of scuffing criteria is that none of them accounts for all of the controlling variables in the contact area. The missing variables include the changes in surface roughness, changes in surface (boundary) films and progression of substrate material toward fatigue failure: these variables have been so convincingly demonstrated in the literature as important to surface survival that it is surprising, and most unfortunate that scuff criteria continue to be discussed without their consideration.

The most common understanding of scuffing is that a lubricated sliding system is in danger of scuffing whenever the thickness of the fluid film between sliding surfaces is less than the average height of asperities on the sliding surface, leading to contact and adhesion [2]. This condition is expressed as $A \leqslant 1$, where $A$ is defined as

$A=\frac{h}{\sigma}$

$h$ is the fluid film thickness as calculated by one of several available equations of elastohydrodynamics, and $\sigma$ is the composite surface roughness of the sliding surfaces 1 and 2, defined by

$\sigma=\left(\sigma_{1}^{2}+\sigma_{2}^{2}\right)^{1 / 2}$

Extensive work suggests that there is some validity to the $A$ criterion, but only in (those rare) systems in which there is a minimum of reactivity between chemically active species in the lubricant and the sliding surfaces [3]. Otherwise the critical value of $A$ is different for every type of surface topography, every type of substrate microstructure, every type of lubricant and every type of break-in process. Further, these four variables are interdependent. In summary, the $A$ criterion is a useful general indicator of relative lubricating conditions but is not reliable as a design tool since its critical value may range from as high as 3 to as low as 0.05 .

There are several thermal criteria for scuffing, but none is convincing in that they are attempts to find the single critical surface temperature rise at which some event intervenes to end effective lubrication. These events most often refer to desorption of lubricant or chemical changes in the lubricant. One interesting thermal theory is based on thermoelastic instability [4]. A local region is thought to heat up by repeated and/ or sustained contact, it expands and stands higher than the surrounding region. Contact between two such regions on opposing surfaces is suggested to initiate scuffing. Experiments to verity this hypothesis were done but with mixed results.

Some interesting work on scuffing was done under the auspices of the IRG of the OECD (Europe) [5]. This work produced maps of transitions between adequately lubricated (partial EHD) and inadequately lubricated sliding of steel on steel, over ranges of applied load and sliding speed. Work of the same type was done while observing the chemical and mechanical changes that take place in the boundary film, using ellipsometry [6]. In this work a soft film, primarily of $\mathrm{Fe}_{3} \mathrm{O}_{4}$ was found to form over lime, which reduced the (dry) friction to half that betore the film formed. This film persisted up to some contact pressure, whereupon it slowly diminished in thickness, and scuffing (surface failure) occurred. A second work following on the method of the IRG focused on further limitations of condition criteria for scuffing [3]. In this work the changes in surface roughness, the electrical conductivity and friction during severe sliding were monitored for many conditions of lubrication. material hardness and microstructure, and initial surface roughness. Surface roughening was found to change the to two separate causes, namely, plastic flow of asperities in shear (probably enhanced by adiabatic heating) and loss of small regions of steel. Friction was low and electrical resistance was high during much of the plastic flow, indicating that direct metal-metal contact or adhesion was not the reason for roughening. The loss of small regions of steel was seen on surfaces in the early stages of scuffing, of the order of the grain size of the steel [7]. The base of these pockets showed clear indications of plastic failure. Some of these pockets appeared as early as 50 cycles of sliding, suggesting a low-cycle fatigue mechanism of material failure. Further, a strong correlation is seen between sliding endurance (contact cycles to the first indication of surface failure) and those tensile properties of metals that correlate with the fatigue life of metals in plastic strain cycling. It appears that fatiguing is a prominent mode of surface failure, which must be included in future criteria for catastrophic failure of surfaces.

\section{The plasticity index}

A scuffing criterion somewhat related to the $A$ criterion is the plasticity index. This concept was developed in several steps, over several years, its important point being that scuffing will occur whenever asperities plastically deform to some small $(2 \%)$ extent during contact. Plastic flow is more likely to occur with materials that are soft but rigid, and where the slopes of the asperities are highest.

Blok began the thinking in 1952 by calculating conditions of normal contact that mark the transition from 
elastic to plastic flow in asperities [8]. He assumed two surfaces of exactly matching sinusoidal ridges, of wavelength $L$, and height $h_{\max }$, contacting each other. When these surfaces are pressed together, the ridges become flattened so that full and flat contact between the bodies is achieved. The maximum stress in the material is calculated by

$\left(\sigma_{\max }\right)_{\mathrm{crit}}=2\left(\sigma_{\mathrm{av}}\right)_{\mathrm{crit}}=\pi\left(\frac{h_{\max }}{L}\right) E^{\prime}$

where $E^{\prime}=E /(1-\nu)$, and $E$ is Young's modulus and $y$ is the Poisson ratio.

The critical value of maximum stress, that which produces plastic flow, can be taken to be equivalent to the hardness $H$ (e.g. Brinell hardness) so that

$\left(\frac{h_{\max }}{L}\right)<\frac{H}{\pi E^{\prime}}$

In essence, this equation states that the average slope of the sinusoidal ridges, $h_{\text {max }} / L$, should be less than $H / \pi E^{\prime}$ in order to prevent plastic flow in the ridge materials. Tabor calculated the consequences of this condition for tool steel of hardness $800 \mathrm{Bhn}$ and found the critical average slope of asperities to be $0.72^{\circ}[9]$. Since the hardness of virtually all materials is less than $800 \mathrm{Bhn}$, and the slope of virtually all practical surfaces is much larger than $0.72^{\circ}$, many authors readily assume that most of the load between two bodies is carried on asperities that are in a state of plastic flow.

Assurance of plastic flow in asperities was called into question by Archard [10]. In 1957 he published a calculation of the area of contact for various arrays of spherically shaped bumps. Hertz (elastic) calculations for a single pair of spheres show that $A \propto W^{2 / 3}$, and the relationship for plastic flow is $A \propto W^{3}$. Archard calculated the relationship between $A$ and $W$ for several arrays of spheres, but one array is particularly interesting, i.e. where a surface consisted of three widely separated scales of superposed spherical bumps. He calculated that $A \propto W^{44 / 45}$. His conclusion was that since $A \propto W^{1}$ is often measured in experiments, practical surfaces could be composed of complicated arrays of elastically deforming asperities and the sinusoidal ridge representation of asperities was not realistic. These suggestions are interesting, but real surfaces are not made up of three widely separated scales of asperities. Rather they are composed of a fairly continuous distribution of asperity sizes, tip radii and asperity heights.

In 1966 Greenwood and Williamson published their own criterion for the initiation of plastic flow in contacting asperities which they called the plasticity index [11]. They had done considerable work on the sizes and shapes of asperities in contact and sought to represent asperities more realistically than did Blok or
Archard. They assumed two flat surfaces pressing against each other, each of them covered with asperities. These asperities were assumed to have spherical shaped tips of average radius $R$, with a gaussian peak height distribution (different from simple height distribution), and were sufficiently widely separated from each other that their strain fields did not overlap. (They were aware that $R$ actually varies by at least a factor of 10 and that this variation has a significant influence on the point of initiation of plastic flow across the entire contacting region.) They then brought the two flat planes together so that the highest asperities touched, and applied loads to compress the asperities. The distance of elastic compressing motion $w$ was connected with the maximum contact stress $q_{0}$ in the highest asperity by the equation of Hertz, in the form

$w=\left(\frac{\pi}{2}\right)^{2} q_{\mathrm{o}}^{2}\left(\frac{R}{E^{\prime}}\right)^{2}$

The critical condition was taken to be the value of $q_{\mathrm{o}} \approx 0.6 \mathrm{H}$, so that the value of $w$ that produced plastic flow in the first asperity to flow was

$w_{\mathrm{p}}=0.89 R\left(\frac{H}{E^{\prime}}\right)^{2}$

This is the condition for the occurrence of the first subsurface plastic flow. The expansion of the plastic flow field to the surface during indentation requires a larger value of $w$ so the equation was simply written as

$w_{\mathrm{p}}=R\left(\frac{H}{E^{\prime}}\right)^{2}$

Then by a statistical argument they declared that some measure of the asperity peak height distribution should be represented in the equation as well. The quantity they used was $\sigma^{*}$ (different from $\sigma$ ), the standard deviation of peak height distribution. Now

$w_{\mathrm{p}}^{*}=\frac{w_{\mathrm{p}}}{\sigma^{*}}=\frac{R}{\sigma^{*}}\left(\begin{array}{l}H \\ E^{\prime}\end{array}\right)^{2}$

which the authors thought incongruously expressed the severity of contact in terms of the inverse of surface roughness. They preferred another format and simply defined $\left(w_{\mathrm{p}}^{*}\right)^{-0.5}$ as more useful. They referred to this quantity as the plasticity index and represented it with the symbol $\Psi$

$\Psi_{\mathrm{GW}}=\frac{E^{\prime}}{H}\left(\frac{\sigma^{*}}{R}\right)^{1 / 2}$

The quantity $\left(\sigma^{*} / R\right)^{1 / 2}$ may actually represent the average slope of asperities, which connects this plasticity index with that of Blok to some extent. 
Another view on the plastic deformation of asperities came from Whitehouse and Archard in 1970 [12]. They disagreed with the Greenwood and Williamson representation of asperity size and shape (tip radius). Whitehouse and Archard also preferred to express the connection between the height of neighboring asperities in terms of an exponential auto correlation function of heights (which ultimately resulted in using an average asperity tip radius as well!). They could then assume correlation distances at will, according to the size of asperities they considered to be important in two-body contact. An exponential auto correlation function of asperity heights favors the low frequencies (large wavelength asperities) as more important than the fine features. Their equation is given in the form

$\Psi_{\mathrm{w}_{\mathrm{A}}}=0.6 \frac{E^{\prime}}{H}\left(\frac{\sigma}{\beta^{*}}\right)$

where $\sigma$ is the standard deviation of height distribution $\sigma_{\mathrm{q}} \cdot \beta^{*}$ is the correlation distance of the surface topography which characterizes the randomness or uniformity of a surface height profile. $\beta^{*} \approx 0$ indicates that surface heights are totally random whereas $\beta^{*}=1$ refers to a flat surface where the surface heights are all interdependent and the same.

The measuring of $\beta^{*}$ is rather involved. It is obtained by selecting a proper exponential function which best fits the auto correlation function plotted with respect to spacings between asperities. The best fit is found by first determining the statistical properties of the surface topography by making measurements at several sampling lengths. Since the large asperity scale is preferred in this analysis, this size scale should first be identified and then the tracer sampling spacing should be set to about $1 / 5$ to $1 / 4$ that scale. Unfortunately, the values of both $\sigma$ and $\beta^{*}$ vary considerably with variations in sampling length so that the value of critical $\Psi$ for initiation of plastic flow cannot be fixed very surely.

The interesting feature of the plasticity index of Whitehouse and Archard is that again, the ratio $\sigma / \beta^{*}$ can be taken as the average slope of the large and important (to them) asperities. Thus it is seen that in principle, all three of the above equations come to the same apparent conclusion that scuffing is strongly influenced by asperity slope, i.e. $h_{\max } / L,\left(\sigma^{*} / R\right)^{1 / 2}$ and $\sigma /$ $\beta^{*}$, although the slopes are very different in magnitude. It will be seen that the average slopes of asperities as measured directly with stylus instruments are different again.

\section{The plasticity index and scuffing}

The concept of the plasticity index as a scutfing criterion was under active discussion in the early $1970 \mathrm{~s}$.
This concept fit well with the general impression that adhesion was enhanced by brcaking up oxides on metal asperities, which involved some plastic deformation of the asperities, and the absence of oxides was thought to promote adhesion.

Hirst and Hollander (1974) did some experiments on the influence of various types of surface roughness on surface damage, using the ball-on-disk configuration [13]. They settled on the representation of surface topography in the plasticity index of Whitehouse and Archard. They slid a hard stainless steel ball, 0.5 in in diameter, one way only, on flat specimens of 18-8 stainless steel (hardness, 180 VPN). Some of the flat specimens were abraded by specific grades of abrasive paper and others were grooved with a hard tool in several ways, to achieve a range of values of both $R_{\mathrm{c}}$ and $\beta^{*}$. They used white mineral oil with $1 \%$ stearic acid as the lubricant. The sliding speed was $25 \mu \mathrm{m}$ $\mathrm{s}^{-1}$, which was a common sliding speed in the early research on boundary lubrication. At this low speed, all effects of the liquid phase of lubricants are negligible, and furthermore, this allows a long time test on a short specimen. In retrospect, it is interesting that they should have selected an ordinarily reactive lubricant with an ordinarily unreactive metal pair for their work.

In one test sequence, using specimens over a range of $\sigma=R_{\mathrm{q}}$ from 0.01 to $1 \mu \mathrm{m}$ and a range of $\beta^{*}$ from 1.8 to $16 \mu \mathrm{m}$, Hirst and Hollander applied a load of $2.5 \mathrm{~N}$ and raised the temperature from 25 to $250^{\circ} \mathrm{C}$ while sliding. They identified a transition as that temperature at which the friction increased markedly. The regions of transition when plotted on $R_{\mathrm{q}}-\beta^{*}$ axes are as shown in Fig. 1. The shaded area was taken to be a region in which scuffing was much less likely to occur than in the surrounding unshaded region. At low values of $R_{\mathrm{c}}$ the transition appears not to be dependent on $\beta^{*}$. At higher values of $R_{\mathrm{q}}$ the transition appears to coincide with lines of constant values of $R_{\mathrm{q}} / \beta^{*}$ (asperity slope), indicating some possibility that the plasticity index concept is valid.

A second series of tests was done at $95{ }^{\circ} \mathrm{C}$ but the load was increased progressively from some low value

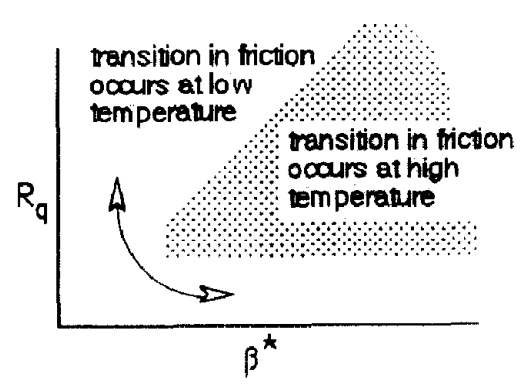

Fig. 1. Regions in which transitions occurred in friction (log scales). 




Fig. 2. Comparison of transition loads and plasticity index values.

until friction increased suddenly. Figure 2 shows the approximate ranges of transition loads on the $R_{\mathrm{q}}-\beta^{*}$ axes. Values of constant $\Psi$ are shown on the same axes. The lines are essentially coincident at low values of $R_{\mathrm{q}}$. This figure suggests a connection between specific transition loads and the plasticity index of Whitehouse and Archard, but the connection is fortuitous. The relevant values of plasticity index of Greenwood and Williamson are fairly close to those of Whitehouse and Archard suggesting that there are two routes to the correct answers. Neither is relevant to the case of scuffing as will be discussed below. It is clear however, that for non-sliding contact a smaller $\Psi$ indicates a smaller amount of plastic contact for a given load. Nivatvongs et al. [14], Cogdell et al. [15], and Poon 116] did some work similar to that of Hirst and Hollander and appeared to support the plasticity index concept. No one has connected their transition or scuff loads with the actual amount of plastic flow in the surfaces however.

\section{Critique of the plasticity index as a scuffing criterion}

Experiments were done to determine if the results of Hirst and Hollander could be duplicated. The flat surface was 303 stainless steel, $77 R_{\mathrm{b}}$ hard. These flat plates were abraded by four abrasives (SiC paper) to achieve specific values of $\sigma$ and $\beta^{*}$, as noted in Table 1. A $440 \mathrm{C}$ ball of stainless steel (diameter, $0 / 5$ in; 58 $R_{\mathrm{c}}$ ) was slid at $23 \mu \mathrm{m} \mathrm{s}^{-1}$ on the flat plate, using mineral oil (heavy, $180 \mathrm{cSt}$ at $22{ }^{\circ} \mathrm{C}$ ) containing $1 \%$ stearic acid. The first experiments were done at $95{ }^{\circ} \mathrm{C}$, using step loading, in which $1.6 \mathrm{~N}$ load was applied, held for $2 \mathrm{~min}$, a second $1.6 \mathrm{~N}$ was added etc., for four steps, followed by additions of $3.2 \mathrm{~N}$ to the maximum of $22.4 \mathrm{~N}$ if necessary. These were conditions near those of Hirst and Hollander. The data of interest was the load at which the coefficient of friction increased suddenly and considerably. The low coefficient of friction was about 0.1 which is generally taken to indicate adequate lubrication. The higher coefficient of friction exceeded 0.3 and was often accompanied by vibrations.

Note that the ordinate of Fig. 3 is shown in terms of nominal contact pressure which is the transition load divided by hertzian calculated area of contact. These units were selected because of a dichotomy that presented itself early in the test program, namely that most of the higher loads left furrows, (plastically deformed ) in flat surfaces. The major problem is that all but the heaviest loads should have produced only elastic global deformation by the principles of the plasticity index. Further, contact pressure was used in plotting the data of all experiments because it was found convenient to bridge the gap between ball-onflat experiments and the later described experiments using the cylinder-on-flat specimens.

The fact of extreme plastic flow in the contact region in the experiments reported above is readily explained. The load that is associated with particular values of $\Psi$ in the work of Greenwood and Williamson can be calculated, in which the major relevant assumption was that the asperities were distributed over a nominally flat surface. Dividing the load by unit area produces a nominal contact pressure, which is plotted versus $\Psi$ in Fig. 4. The data in Fig. 3 are replotted in Fig. 4 as well. Figure 4 shows the very different stress state in the ball-on-flat test from that assumed by Greenwood and Williamson.

Another difficulty in attempts to apply the plasticity index concept as a scuffing criterion is that the average asperity slope is improperly represented. This may be seen in Fig. 5, which compares the calculated slopes used by Hirst and Hollander (after Whitehouse and Archard) and the measured slopes in the present work. Whitehouse and Archard suggested that the average slope of asperities should be $m_{\text {avg }} \approx 0.24\left(\sigma / \beta^{*}\right)$. Figure 5 shows the data of Hirst and Hollander plotted according to their calculations and the data of the present work plotted against measured $m_{\text {avg. }}$. The difference suggests that the proper relationship would be $m_{\text {avg }} \approx(\sigma /$ $\left.\beta^{*}\right)$. Recall that Whitehouse and Archard selected the large or long wavelength asperities for consideration, but the values used by Hirst and Hollander in Fig. 5 appear to represent waviness more than large asperities.

All of the slopes of the Hirst and Hollander asperities are calculated to be less than the smoothest specimen used in the present work $\left(R_{\mathrm{a}} \approx 0.038 \mu \mathrm{m}\right)$, although they probably had some surfaces equivalent to those of the present work.

\section{Extension of scuffing studies toward practical systems}

Absolute values of $\Psi$ appear not to provide useful guidelines for predicting scuffing. Furthermore, stainless 
TABLE 1. Values of $\sigma, \beta^{*}, \Psi$ and average asperity slope (tangent) of surfaces abraded by four methods, for AISI 303 stainless steel flat specimens, $77 \mathrm{Rb}$ hard

\begin{tabular}{|c|c|c|c|c|c|c|c|}
\hline Notation & $\begin{array}{l}R_{\mathrm{a}} \\
(\mu \mathrm{m})\end{array}$ & $\begin{array}{l}R_{\mathrm{q}} \\
(\mu \mathrm{m}) \\
\text { (measured) }\end{array}$ & $R_{\mathrm{dat}}$ & $\begin{array}{l}\beta^{*} \\
(\mu \mathrm{m}) \\
\text { (presumed) }\end{array}$ & $\begin{array}{l}\Psi \\
\text { (calculated) }\end{array}$ & $\begin{array}{l}\text { Transition } \\
\text { load } \\
\text { vy }\end{array}$ & $\begin{array}{l}\text { Hartz } \\
\text { pressure } \\
(\mathrm{GPa})\end{array}$ \\
\hline $\begin{array}{l}\text { n600 } \\
\text { (new } 600 \text { grit) }\end{array}$ & 0.064 & 0.089 & 0.04 & 3.8 & 1.1 & 98 & 0.55 \\
\hline $\begin{array}{l}\text { w600 } \\
\text { (worn } 600 \text { grit) }\end{array}$ & 0.038 & 0.051 & 0.029 & 3.8 & 0.6 & 1.38 & 061 \\
\hline $\begin{array}{l}\text { n240 } \\
\text { (new } 240 \text { grit) }\end{array}$ & 0.267 & 0.343 & 0.055 & 5.0 & 3.3 & 16 & 0.3 \\
\hline $\begin{array}{l}\text { w240 } \\
\text { (worn } 240 \text { grit) }\end{array}$ & 0.089 & 0.114 & 0.038 & 5.0 & 1.1 & 4.8 & 0.43 \\
\hline
\end{tabular}



Fig. 3. Nominal contact pressure of transition load vs. plasticity index of AISI 303 flat in single-pass sliding with $1 \%$ stearic acid solution of heavy mineral oil.

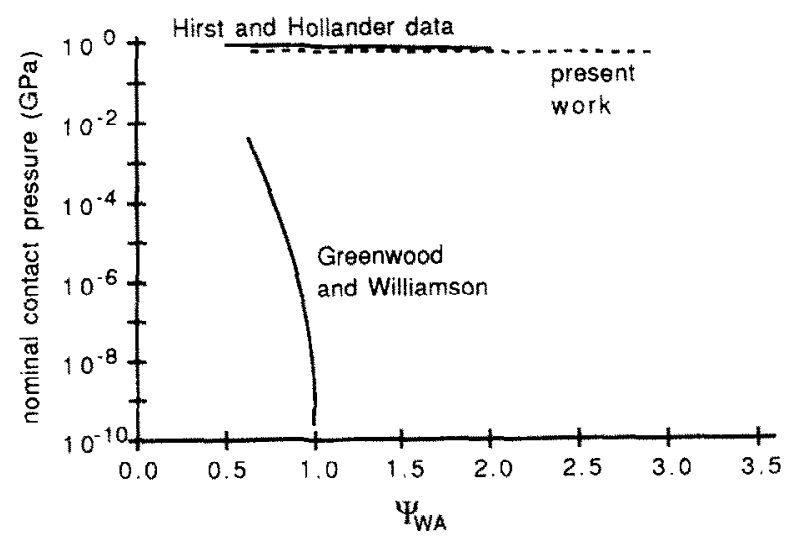

Fig. 4. Comparison of the contact pressure at transition load of Hirst and Hollander and the present work with theoretical critical pressure for onset of plastic deformation in asperities by Greenwood and Williamson.

steel, very low sliding speeds and single-pass sliding are conditions far removed from practical systems in which scuffing is ordinarily to be prevented. To gain a perspective on the extent to which some variables in the plasticity index may apply in practice, further experiments were done. These tests included some with

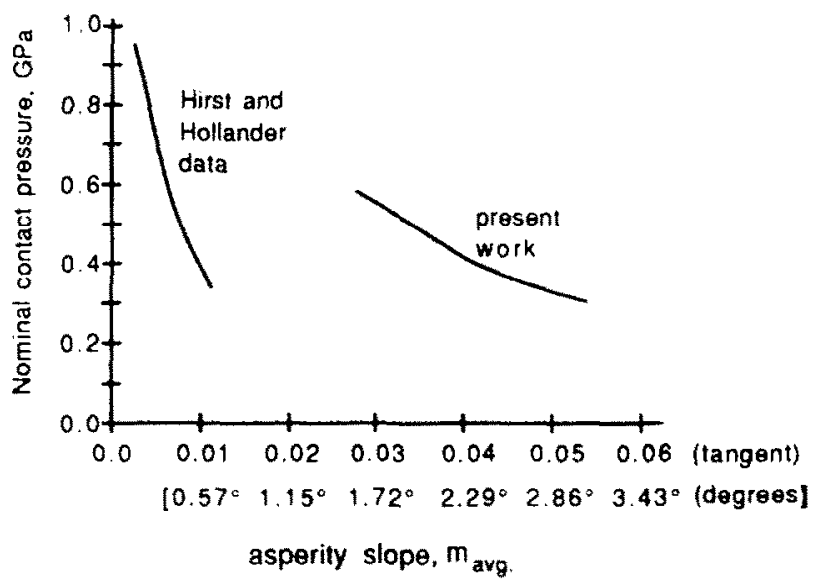

Fig. 5. Average slope (tangent) of asperities $\left(m_{\mathrm{avg}}\right) v s$. nominal contact pressure of the transition load of AISI 303 flat in single pass sliding with $1 \%$ stearic acid solution of heavy mineral oil.

the ball-on-flat, low speed, single-pass device described above but with low alloy (non-stainless) stecl and unreactive lubricants. The conditions of the tests are listed in Table 2.

The transition loads were all divided by the hertzian contact region to provide nominal contact pressure as before. The data for all of the tests are plotted in Fig. 6 , against $\Psi$ as the abscissa. The influences of the individual variations may be seen by comparing Fig. 6 with Table 2.

It may be seen that whereas Hirst and Hollander used chemically resisting stainless stecl, the addition of stearic acid into the mineral oil had some effect on the scuffing load, but small compared with the effect of stearic acid in oil on low alloy steels. Further, the low alloy steel pairs produced a positive slope on the axis of Fig. 6 whereas stainless steel produced a negative slope. In some way, the stearic acid and the rougher asperities interacted together to increase the transition load.

For a closer approach to practical conditions, some tests were done with a cylinder-on-flat plate, in repeat 
TABLE 2. List of the test conditions in ball-on-flat, single-pass sliding

\begin{tabular}{|c|c|c|c|c|c|}
\hline $\begin{array}{l}\text { Test } \\
\text { condition }\end{array}$ & $\begin{array}{l}\text { Flat } \\
\text { specimen }\end{array}$ & Slider & Lubricant & $\begin{array}{l}\text { Temperature } \\
\left({ }^{\circ} \mathrm{C}\right)\end{array}$ & $\begin{array}{l}\text { Number of } \\
\text { roughnesses }\end{array}$ \\
\hline$\# 1$ & $\begin{array}{l}\text { AISI } 303 \\
\left(77 R_{\mathrm{b}}\right)\end{array}$ & $\begin{array}{l}\text { AISI } 440 \mathrm{C} \\
\left(48 R_{c}\right)\end{array}$ & $\begin{array}{l}1 \% \text { stearic acid } \\
\text { solution in heavy } \\
\text { mineral oil } \approx 8.5 \mathrm{cSt}\end{array}$ & 95 & $\begin{array}{l}4 \text { (reported above } \\
\text { as present work) }\end{array}$ \\
\hline$\# 2$ & $\begin{array}{l}\text { AISI } 303 \\
\left(77 R_{b}\right)\end{array}$ & $\begin{array}{l}\text { AISI } 440 \mathrm{C} \\
\left(48 R_{\mathrm{c}}\right)\end{array}$ & $\begin{array}{l}\text { heavy mineral oil } \\
\approx 8.5 \mathrm{cSt}\end{array}$ & 95 & 1 \\
\hline$\# 3$ & $\begin{array}{l}\text { AISI } 303 \\
\left(77 R_{\mathrm{b}}\right)\end{array}$ & $\begin{array}{l}\text { AISI } 440 \mathrm{C} \\
\left(48 R_{c}\right)\end{array}$ & $\begin{array}{l}\text { heavy mineral oil } \\
180 \mathrm{cSt}\end{array}$ & 22 & 1 \\
\hline$\# 4$ & $\begin{array}{l}\text { AISI } 303 \\
\left(77 R_{\mathrm{b}}\right)\end{array}$ & $\begin{array}{l}\text { AISI } 440 \mathrm{C} \\
\left(48 R_{\mathrm{c}}\right)\end{array}$ & $\begin{array}{l}\text { light mineral oil } \\
45 \mathrm{cSt}\end{array}$ & 22 & 4 \\
\hline$\# 5$ & $\begin{array}{l}\text { AISI } 303 \\
\left(77 R_{\mathrm{b}}\right)\end{array}$ & $\begin{array}{l}\text { AISI } 52100 \\
\left(52 R_{\mathrm{c}}\right)\end{array}$ & $\begin{array}{l}\text { light mineral oil } \\
45 \mathrm{cSt}\end{array}$ & 22 & 4 \\
\hline$\not \# 6$ & $\begin{array}{l}\text { AISI } 4340 \\
\left(8 R_{\mathrm{c}}\right)\end{array}$ & $\begin{array}{l}\text { AISI } 52100 \\
\left(52 R_{\mathrm{c}}\right)\end{array}$ & $\begin{array}{l}1 \% \text { stearic acid } \\
\text { solution in heavy } \\
\text { mineral oil } \approx 8.5 \mathrm{cSt}\end{array}$ & 95 & 4 \\
\hline$\not 7$ & $\begin{array}{l}\text { AISI } 4340 \\
\left(8 R_{\mathrm{c}}\right)\end{array}$ & $\begin{array}{l}\text { AISI } 52100 \\
\left(52 R_{\mathrm{c}}\right)\end{array}$ & $\begin{array}{l}\text { light mineral oil } \\
45 \mathrm{cSt}\end{array}$ & 22 & 1 \\
\hline$\# 8$ & $\begin{array}{l}\text { AISI } 4340 \\
\left(8 R_{c}\right)\end{array}$ & $\begin{array}{l}\text { AISI } 440 \mathrm{C} \\
\left(58 R_{c}\right)\end{array}$ & $\begin{array}{l}\text { light mineral oil } \\
45 \mathrm{cSt}\end{array}$ & 22 & 4 \\
\hline
\end{tabular}



Fig. 6. Plot of nominal contact pressure at transition to high friction, vs. $\Psi$, coded to the conditions listed in Table 2 .

or multiple pass sliding and at higher sliding speeds. The cylinder was of 0.25 in diameter and 0.25 in length. The step loads varied from $93 \mathrm{~N}$ to $1519 \mathrm{~N}$, in 2 min steps, beginning at $62 \mathrm{~N}$. These loads produced contact pressures corresponding to those used in the previous tests. The sliding speed was $0.3 \mathrm{~m} \mathrm{~s}^{-1}$, approximately 13000 times faster than in the previous tests.

Some of the same material combinations were used as in the single-pass tests, but the surface roughnesses were formed somewhat differently for the repeat pass tests to conform with more common practice. The four methods of preparing the surfaces, are identified as fine, medium, rough and ground. The roughness, $R_{\mathrm{q}}$ and the average slopes of asperities for the specimens, $R_{\mathrm{da}}$, are shown in Fig. 7. The materials used in the

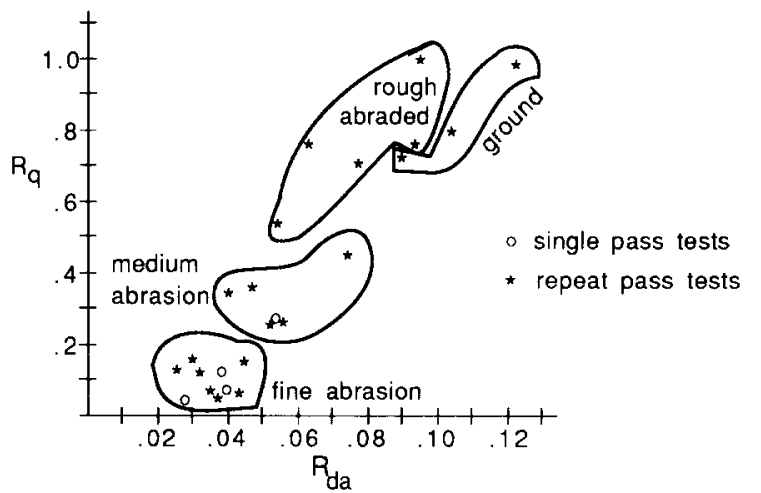

Fig. 7. Comparison of $R_{\mathrm{q}}(\mu \mathrm{m})$ and $R_{\mathrm{da}}$ (average slope of asperities) for the specimens used in the cylinder-on-flat tests.

cylinder-on-flat tests are listed in Table 3. The load step and nominal contact pressure at which scuffing (friction rise) occurred is also given in Table 3.

The results of the tests are plotted in Fig. 8. In comparing the results within Fig. 8 it may be seen that low alloy steel (\#9) is much more resistant to scuffing than is stainless steel (\#10). Steel with plain mineral oil (\#11) is at least as scuff resistant as is stainless steel with mineral oil plus stearic acid (\#10). Scuff resistance is somewhat related to hardness (\#11\#12-\#13).

Comparing Fig. 6 with Fig. 8, tests \#6 and \#9 are similar, and tests \#7 and \#11 are similar except that \#6 and \#7 are single-pass tests, \#9 and \#11 are multiple-pass tests. Comparing \#6 with \#9 shows that repeat-pass tests of low alloy (non-stainless) steel in 
TABLE 3. Specimen composition, roughness, conditions of test and scuff load of each. The slider was a cylinder of 52100 , 60 ir in all cases

\begin{tabular}{|c|c|c|c|c|c|c|c|c|c|}
\hline $\begin{array}{l}\text { Test } \\
\text { series }\end{array}$ & $\begin{array}{l}\text { Flat } \\
\text { steel }\end{array}$ & $\begin{array}{l}\text { Lubricant } \\
\text { (additive) }\end{array}$ & $\begin{array}{l}\text { Temperature } \\
\text { of test }\end{array}$ & $\begin{array}{l}\text { Finish } \\
\text { method }\end{array}$ & $\begin{array}{l}R_{x} \\
(\mu \mathrm{m})\end{array}$ & $\begin{array}{l}R_{4} \\
(\mu \mathrm{m})\end{array}$ & $\begin{array}{l}R_{\mathrm{da}} \\
(\tan )\end{array}$ & $\begin{array}{l}\text { Sculf } \\
\text { load }(N)\end{array}$ & $\begin{array}{l}\text { Nominal control } \\
\text { pressure }\end{array}$ \\
\hline \multirow[t]{5}{*}{$\# 9$} & \multirow{5}{*}{$\begin{array}{l}4340 \\
8 R_{\mathrm{c}} \\
(175 \mathrm{Bhn})\end{array}$} & $\mathrm{HMO}^{\mathrm{a}}$ & \multirow[t]{5}{*}{$95^{\circ} \mathrm{C}$} & fine-1 & 0.038 & 0.051 & 0.039 & 155 & $0.38 \mathrm{GPa}$ \\
\hline & & $(1 \%$ & & fine-? & 0.057 & 0.07 & 0.044 & :' & $\therefore 119$ \\
\hline & & stearic & & med-1 & 0.18 & 0.25 & 0.053 & $\%$ & $>1.19$ \\
\hline & & acid) & & med-2 & 0.36 & 0.46 & 0.076 & $*$ & $\therefore 1,19$ \\
\hline & & & & rough & 0.76 & 0.99 & 0.096 & $*$ & $>1.19$ \\
\hline \multirow[t]{4}{*}{$\not 10$} & 303SS & $\mathrm{HMO}$ & \multirow[t]{4}{*}{$95^{\circ} \mathrm{C}$} & fine-1 & 0.051 & 0.07 & 0.038 & 155 & 0.38 \\
\hline & \multirow{3}{*}{$\begin{array}{l}77 R_{\mathrm{b}} \\
(132 \mathrm{Bhn})\end{array}$} & $(1 \%$ & & fine-2 & 0.114 & 0.152 & 0.046 & 217 & 0.45 \\
\hline & & stearic & & med & 0.191 & 0.254 & 0.058 & 217 & 0.45 \\
\hline & & acid) & & rough & 0.51 & 0.7 & 0.079 & 155 & 0.38 \\
\hline \multirow[t]{4}{*}{$\# 11$} & 4340 & $\mathrm{LMO}^{\mathrm{b}}$ & \multirow[t]{4}{*}{$22^{\circ} \mathrm{C}$} & fine & $0.0 \% 5$ & 0.127 & 0.033 & 155 & 0.38 \\
\hline & \multirow{3}{*}{$\begin{array}{l}8 K_{\mathrm{c}} \\
(175 \mathrm{Bhn})\end{array}$} & (none) & & med & 0.241 & 0.343 & 0.041 & 279 & 0.51 \\
\hline & & & & rough & 0.57 & 0.76 & 0.095 & 341 & 0.56 \\
\hline & & & & ground & 0.76 & 0.97 & 0.125 & 403 & 0.61 \\
\hline \multirow[t]{4}{*}{$\# 12$} & \multirow{4}{*}{$\begin{array}{l}4340 \\
35 R_{c} \\
(350 \mathrm{Bhn})\end{array}$} & LMO & \multirow[t]{4}{*}{$22{ }^{\circ} \mathrm{C}$} & fine & 0.127 & 0.165 & 0.031 & 527 & 0.70 \\
\hline & & (none) & & med & 0.28 & 0.37 & 0.048 & 890 & 0.9 \\
\hline & & & & rough & 0.58 & 0.76 & 0.064 & 527 & 0.70 \\
\hline & & & & ground & 0.61 & 0.79 & 0.105 & 527 & 0.70 \\
\hline \multirow[t]{3}{*}{$\# 13$} & \multirow{3}{*}{$\begin{array}{l}4340 \\
56 R_{\mathrm{c}} \\
(555 \mathrm{Bhn})\end{array}$} & LMO & \multirow[t]{3}{*}{$22^{\circ} \mathrm{C}$} & fine & 0.083 & 0.114 & 0.027 & 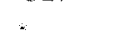 & $>1.19$ \\
\hline & & (none) & & rough & 0.41 & 0.53 & 0.056 & 1023 & 0.97 \\
\hline & & & & ground & 0.56 & 0.71 & 0.091 & 837 & 0.88 \\
\hline
\end{tabular}

${ }^{a} \mathrm{HMO}$ refers to heavy mineral oil $\left(180 \mathrm{cSt}\right.$ at $22^{\circ} \mathrm{C}, 8.5 \mathrm{cSt}$ at $\left.95^{\circ} \mathrm{C}\right)$.

${ }^{b} \mathrm{LMO}$ refers to light mineral oil $\left(45 \mathrm{cSt}\right.$ at $\left.22^{\circ} \mathrm{C}\right)$.

'Refers to scuff load beyond the capacity of the machine.

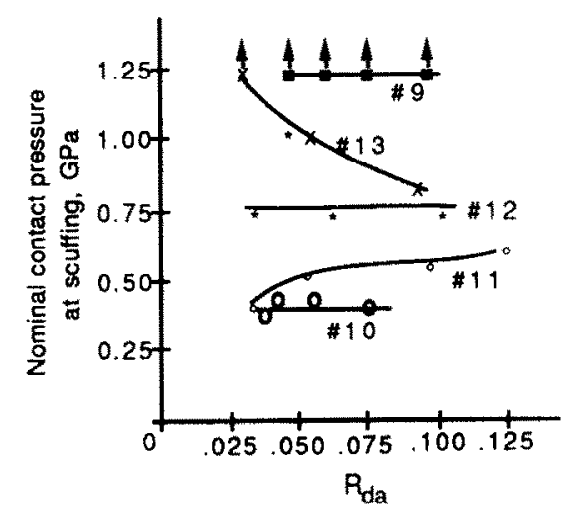

Fig. 8. Plot of nominal contact pressure at scuffing $v$ s, the average slope of asperities in the cylinder-on-flat test.

a reactive environment produces higher load-carrying capacity. Apparently a protective film forms during repeat-pass sliding while the step loading is increasing.

Comparing \#7 with \#11 suggests that repeat-pass sliding (with step loading) in non-reactive lubricant does not significantly increase load-carrying capacity.

\section{Global plastic flow criterion for scuffing}

It has been obvious through all this work that the actual strains in the asperities at the point of scuffing are significantly greater than the $2 \%$ assumed in the discussions of the plasticity index. Actual strains were not determined but a crude estimate can be made by considering the global strain state in the flat surface indented by a ball. Recall that the condition for first plastic flow requires $p_{\mathrm{m}} \approx 1.1 Y$. The range of $p_{\mathrm{m}}$ at scuffing for all tests is shown in Table 4.

Now considering that the real contact area is significantly smaller than the apparent area, the contact pressure on the contacting asperities must be well in the plastic range, although by an unknown amount. Furthermore, for the condition of $\mu=0.1$ the effective stress in asperities, by von Mises, rises by about $14 \%$ from that in normal contact, and for $\mu=0.2$ it rises about $26 \%$. Very likely the shear stress condition on asperities is equivalent to a much higher value, where the global value of $\mu \approx 0.1$ or 0.2 . Thus it is hardly necessary to resort to a plasticity index when simple calculations show that asperities, scuffing or not, flow plastically by a considerable amount.

\section{Discussion}

Of the two implications within the plasticity index, the suggestion that scuffing occurs in the early stages of plastic flow cannot be supported. Furthermore, the influence of asperity slope cannot be taken as universal, either since most curves in Fig. 6 are either flat or 
TABIE 4 . The range of $p_{\mathrm{m}}$ at scuffing for all tests

\begin{tabular}{|c|c|c|c|c|c|c|}
\hline \multicolumn{3}{|c|}{ Flat specimen } & \multicolumn{2}{|c|}{ Yield strength, $Y$} & \multirow{2}{*}{$\begin{array}{l}p_{\mathrm{m}} \text { at scuff } \\
(\mathrm{GPa})\end{array}$} & \multirow{2}{*}{$\begin{array}{l}\text { Ratio } \\
\left(p_{\mathrm{m}} / Y\right)\end{array}$} \\
\hline Material & Rockwell C & Bhn $(\approx 3 Y)$ & $\left(\mathrm{kg} \mathrm{mm}^{-2}\right)$ & $(\mathrm{GPa})$ & & \\
\hline 4340 & 8 & 175 & 55 & 0.54 & $0.42->1.19$ & $0.78->2.2$ \\
\hline 4340 & 35 & 350 & 117 & 1.11 & 0.7 to 0.9 & $0.6-0.79$ \\
\hline 4340 & 56 & 555 & 185 & 1.81 & 0.88 to $>1.1 .9$ & $0.49-0.66$ \\
\hline $303 \mathrm{ss}$ & $77 R_{\mathrm{b}}$ & 132 & 44 & 0.43 & 0.3 to 0.55 & $0.70-1.28$ \\
\hline
\end{tabular}

have positive slopes. A negative slope in Fig. 6 is equivalent to a condition that passes from a safe condition to an unsafe condition in Fig. 2.

Curves $4-8$ in Fig. 6 show virtual independence of scuffing load from asperity slope as defined by $\Psi$, and except for curve 13 in Fig. 8 scuffing load is also independent of measured average asperity slope.

Most of the curves are very different from the data of Hirst and Hollander, for no obvious reason. It is surprising that Hirst and Hollander selected stainless steel and a chemically reactive lubricant to prove a theory derived from contact mechanics, in which no assumptions are made concerning surface chemistry.

However, surface chemistry appears to be prominent, as seen in the high load-carrying capacity of low alloy steels, with and without stearic acid in the oil. Actually the plasticity index would not apply to the case of chemically inert, oxide-free metals since mere contact would result in seizure without even applying a normal load.

The independence of scuffing load from asperity slope may indicate that the roughness of the surfaces is not in the range where roughness has an influence. This is seen at low roughness in Figs. 1 and 2. There may also be a range at high roughness where asperity slope has no effect. Further work is required to resolve this issue.

\section{Conclusion}

The plasticity index is not a useful indicator of the tendency for lubricated metal surfaces to scuff. It appears to have been verified by previous authors but with the uncommon condition of single-pass, low speed sliding, using sphere-on-flat specimens of stainless steel and a chemically active lubricant. Clearly, scuffing of practical surfaces is associated with a great amount of plastic flow in asperities rather than the very small amount implied in the plasticity index.

\section{References}

1 Research Group on Wear of Engineering Materials, Glossan of Terms and Definitions in the Field of Friction, Wear and Lubrication, (European) Organization for Economic Co-operation and Development, Paris, 1969, p. 53.

2 A. Beerbower, ASLE Trans., 14 (1971) 90-104.

3 Y. Lee and K.C. Ludema, J. Tribology, 113 (2) (1991) 295-302.

4 P.M. Ku, ASLE Trans., 19 (1976) 239.

5 A. Begelinger and A.W.J. de Gee, J. Lubr. Technol., 103 (1981) 203-210.

6 S.-C. Kang and K.C. Ludema, Wear, 108 (1986) 375.

7 Q.-J. Xue and K.C. Ludema, Proc. Conf. on Wear of Materials, ASME, Vancouver, 1983.

8 H. Blok, Proc. General Discussion on Lubrication and Lubricants, The Institution of Mechanical Engineers, London, Vol. 2, 1937, pp. 222-235.

9 D. Tabor, Proc. R. Soc. (London), A212 (1952) 482.

10 J.F. Archard, Proc. R. Soc. (London), A243 (1957) 190-205.

11 J.A. Greenwood and J.B.P. Williamson, Proc. R. Soc. (London), A295 (1966) 300-319.

12 D.J. Whitehouse and J.F. Archard, Proc. R. Soc. (London), A316 (1970) 97-121.

13 W. Hirst and A.E. Hollander, Proc. R. Soc. (London), A337 (1974) 379-394.

14 K. Nivatvongs, H.S. Cheng, T.C. Ovaert and W.R.D. Wilson, Wear, 143 (1991) 137-148.

15 J.D. Cogdell, M.C. Dawson, F.F. Ling and S.F. Murray, 1987, ASLE Trans., 30 (2) (1987) 141-148.

16 C.Y. Poon, 1990, The influence of surface topography on sliding friction in boundary lubrication, Ph.D. Thesis, Imperial College, London, 1990. 